Article

\title{
Anti-Inflammatory Properties, Bioaccessibility and Intestinal Absorption of Sea Fennel (Crithmum maritimum) Extract Encapsulated in Soy Phosphatidylcholine Liposomes
}

\author{
Ailén Alemán *, Daniel Marín-Peñalver, Pilar Fernández de Palencia, María del Carmen Gómez-Guillén \\ and Pilar Montero*iD
}

Citation: Alemán, A.;

Marín-Peñalver, D.; de Palencia, P.F.;

Gómez-Guillén, M.d.C.; Montero, P.

Anti-Inflammatory Properties,

Bioaccessibility and Intestinal

Absorption of Sea Fennel (Crithmum maritimum) Extract Encapsulated in

Soy Phosphatidylcholine Liposomes.

Nutrients 2022, 14, 210. https://

doi.org/10.3390/nu14010210

Academic Editor: Anna

Gramza-Michałowska

Received: 25 November 2021

Accepted: 1 January 2022

Published: 4 January 2022

Publisher's Note: MDPI stays neutral with regard to jurisdictional claims in published maps and institutional affiliations.

Copyright: (C) 2022 by the authors. Licensee MDPI, Basel, Switzerland. This article is an open access article distributed under the terms and conditions of the Creative Commons Attribution (CC BY) license (https:// creativecommons.org/licenses/by/ $4.0 /)$.
Institute of Food Science, Technology and Nutrition (ICTAN-CSIC), Ciudad Universitaria, 28040 Madrid, Spain; dmarin@ictan.csic.es (D.M.-P.); pfpalencia@ictan.csic.es (P.F.d.P.); cgomez@ictan.csic.es (M.d.C.G.-G.)

* Correspondence: ailen@ictan.csic.es (A.A.P.); mpmontero@ictan.csic.es (P.M.G.)

\begin{abstract}
A sea fennel (Crithmum maritimum) aqueous extract was prepared and loaded into soybean phosphatidylcholine liposomes. Both the free extract (FE), and the empty (L) and loaded (L-FE) liposomes were shown to be non-cytotoxic to THP-1 and Caco-2 cells. The anti-inflammatory effect was tested on THP-1 cells differentiated into macrophages. FE showed anti-inflammatory activity, revealed by the induced secretion of IL-10 cytokines in macrophages that were subsequently stimulated with LPS. Also, a decrease in TNF- $\alpha$ production by L was observed, evidencing that liposomes reduced the pro-inflammatory mediators' secretion. The liposomes $(\mathrm{L})$ showed protective anti-inflammatory activity and also were able to downregulate the inflammation. Furthermore, L-FE were also found to downregulate the inflammation response, as they were able to decrease TNF- $\alpha$ secretion in macrophages previously exposed to LPS. The simulated in vitro gastrointestinal digestion (GID) of FE diminished the chlorogenic acid content (the main polyphenolic compound of the extract) by $40 \%$, while in L-FE, the amount of this phenolic compound increased with respect to the undigested liposomes. The amount of bioaccessible chlorogenic, however, was similar for FE and L-FE. The percentage of chlorogenic acid absorbed through a Caco- 2 cell monolayer after $3 \mathrm{~h}$ of incubation, was significantly similar for the extract and the liposomes $(\sim 1.5 \%)$, without finding significant differences once the extract and liposomes were digested.
\end{abstract}

Keywords: sea fennel; phosphatidylcholine liposomes; anti-inflammatory properties; chlorogenic acid; gastrointestinal digestion; intestinal absorption

\section{Introduction}

Crithmum maritimum, commonly named sea fennel, is an edible halophile plant that is very abundant on the Mediterranean and Atlantic seacoasts. Sea fennel is especially used in gourmet cuisine, or very locally, being an underutilized plant. In previous work, the polyphenolic composition profile of sea fennel aqueous and ethanolic extracts, and their antioxidant properties were studied [1]. It was observed that its main component was chlorogenic acid, which some studies have related to the antioxidant activity of sea fennel [1,2], as well as to other properties associated with disease prevention, such as anticarcinogenic and antimutagenic activities [2], although there are still few studies on this regard.

Given the high amount of chlorogenic acid present in sea fennel [1,3], to which outstanding antioxidant and anti-inflammatory properties have been attributed [4], sea fennel extract may also have a beneficial effect on inflammation mediators. In this sense, several studies have shown how various polyphenols, including hydroxychinamic acids, increase the activation of the immune system response [5,6]. On the other hand, it has also been observed that phospholipids act as lipidic mediators of inflammation [7]. The use of 
macrophages is an ex vivo human system, among others, considered adequate and widely used to study the intracellular cytokine expression pathways [8].

Thus, the biotransformation suffered by phenolic compounds during the digestive process and their subsequent intestinal absorption will determine their bioactive effect on the body. The absorption of most phenolic compounds takes place mainly in the small intestine. Most polyphenols are stable to the action of gastric acids [9] therefore neither hydrolysis nor absorption in this phase of the digestive process occurs, allowing them to reach the intestine in their native form. Some phenolic compounds, such as caffeic acid, are absorbed in the stomach owing to their non-ionized form. On the contrary, their esterified analogs, as is the case of chlorogenic acid, usually pass through the stomach [10] and the small intestine intact, most of them reaching the colon, where the colonic microflora probably transforms them on account of their esterase activity [11].

Several studies confirm that the in vitro determination of permeability, through models based on artificial membranes using cell cultures (Caco- 2 cells), can help predict the in vivo absorption of compounds [11,12]. In particular, some studies have confirmed an absorption transport for chlorogenic acid, although the percentage of this phenolic compound recovered in the basolateral compartment has been quite low in all cases studied, with values below $3 \%$ of the initial amount in the food matrix [11-13].

There are various reasons to protect or encapsulate bioactive compounds, some of them are technological, to avoid flavors or interactions with other components in the food matrix, but there are also others, as it allows the possibility to protect the compounds against GID, favoring their intestinal absorption. Different strategies have been conducted in order to improve the intestinal absorption of chlorogenic acid, including its encapsulation in liposomes. According to Li et al. [14], encapsulation of polyphenols can enhance their absorption and bioavailability due to their low solubility as well as to their low stability and permeability in the GI tract, although nanoparticle stability during GID must also be considered. In this sense, Feng et al. [15], managed to increase 1.29 times the bioavailability of chlorogenic acid extract by using soy phosphatidylcholine and cholesterol liposomes (6:1 WW liposome/chlorogenic) in an in vivo study, concluding that encapsulation in liposomes may be a good mechanism to improve the bioavailability of the bioactive compounds which had been encapsulated. The bioavailability of phenolic compounds, in general, is limited in the human body. Manach et al. [16], found in a large review of 97 human trials that, after the intake of $50 \mathrm{mg}$ of total phenol equivalents, a plasmatic concentration of total metabolites between 0 and $4 \mu \mathrm{M}$ was reached.

In previous work, the encapsulation of two sea fennel extracts (aqueous and ethanolic) in soy phosphatidylcholine liposomes was studied, as well as their most suitable concentrations for good entrapment efficiency and their antioxidant properties [1].

This work aimed to explore the potential anti-inflammatory properties of sea fennel aqueous extract in its free form and encapsulated in liposomes of partially purified soy phosphatidylcholine in order to be considered for food applications. Subsequently, the in vitro bioavailability of both the extract without encapsulation and the extract protected in liposomes was evaluated. In order to do so, the effect of the gastrointestinal digestion process on the phenolic composition of the extract and the filled liposomes was previously determined. Later, the absorption in an intestinal epithelium model was carried out, using bicameral permeable supports with Caco-2 cell monolayers, and evaluating chlorogenic acid as the major phenolic compound in the extract.

\section{Materials and Methods}

\subsection{Materials and Chemical Reactive}

Sea fennel (Crithmum maritimum) was kindly provided by Portomuiños S.L. (Cerceda, A Coruña, Spain). Soybean lecithin was purchased from Manuel Riesgo S.A. (Madrid, Spain). The standard of chlorogenic acid was acquired from Sigma-Aldrich (St. Louis, MO, USA). Ethanol, methanol, and acetonitrile were acquired from Panreac Química S.L.U. (Barcelona, Spain). 


\subsection{Preparation of Aqueous Sea Fennel Extract}

The sea fennel extract (FE) was prepared in distilled water as described in Alemán et al. [1], heating at $60^{\circ} \mathrm{C}$ for $30 \mathrm{~min}$ and sonicating (model Q700, Qsonica, CT, USA) at $114 \mathrm{~W}$ for $5 \mathrm{~min}$. The dispersion was centrifuged at $9000 \times \mathrm{g} \mathrm{rpm}$ (Sorwal RC-5B, Sorwal Instruments, Ramsey, MN, USA) and $4{ }^{\circ} \mathrm{C}$ for $15 \mathrm{~min}$. The resulting supernatant was filtered through Whatman No. 1 paper, freeze-dried, and stored at $-20^{\circ} \mathrm{C}$.

\subsection{Preparation of Liposomes}

The liposomal dispersion from partially purified soy phosphatidylcholine (L) and the liposomes loaded with the sea fennel extract (L-FE) was prepared as previously described by Alemán et al. [1]. The amount of sea fennel extract selected to load the liposomes was $64 \%$ ( $w / w$ with respect to phosphatidylcholine).

The characterization of the liposomes was previously carried out by Alemán et al. [1] where Dynamic Light Scattering analysis of loaded liposomes rendered a z-average of $137.1 \pm 0.7 \mathrm{~nm}$, polydispersity index (PDI) of $0.370 \pm 0.018$, and electronegative Z potential of $-27.7 \pm 2.8$. The entrapment efficiency was $65 \%$.

\subsection{Cell Viability}

Caco-2 cells from human colonic adenocarcinoma and a THP-1 cell line were obtained from the human cell bank at the Centro de Investigaciones Biológicas Margarita Salas (CSIC) (Madrid, Spain). Caco-2 cells $\left(1 \times 10^{5} / \mathrm{mL}\right)$ were maintained in Men-Alpha Medium (Invitrogen, Barcelona, Spain) supplemented with 10\% $(v / v)$ heat-inactivated fetal bovine serum (Gibco Life Technologies, Grand Island, NY, USA), and streptomycin $(100 \mu \mathrm{g} / \mathrm{mL})$ and penicillin (100 U/mL) (Gibco Life Technologies) at $37{ }^{\circ} \mathrm{C}$ in an atmosphere containing $5 \% \mathrm{CO}_{2}$. The culture medium was replaced every three days. THP-1 cells $\left(2 \times 10^{5} / \mathrm{mL}\right)$ were maintained in RPMI 1640 Medium (Gibco Life Technologies) supplemented as described above and were differentiated into macrophages by adding a final concentration of $25 \mathrm{nM}$ of phorbol 12-myristate13-acetate (PMA) (Sigma-Aldrich, St. Louis, MO, USA) after incubating for $72 \mathrm{~h}$, as described Lund et al. [17]. The cells became adherent and PMA was washed using a pre-warmed RPMI, then they were cultured for $24 \mathrm{~h}$ in this medium.

For cell viability, Caco- 2 cells were seeded at $10^{4}$ cells/wells in $100 \mu \mathrm{L}$ complete culture medium into a 96-well tissue culture plates (Falcon Microtest ${ }^{\mathrm{TM}}$, Franklin Lakes, NJ, USA) and incubated to reach $80-90 \%$ confluent cells, approximately for two or three days, at $37{ }^{\circ} \mathrm{C}$ and $5 \% \mathrm{CO}_{2}$. THP1- cells, $10^{5}$ cells/wells in $100 \mu \mathrm{L}$ complete culture medium, were differentiated into macrophages with PMA, and afterward, they were pre-warmed with $100 \mu \mathrm{L}$ RPMI as described previously. Then $10 \mu \mathrm{L}$ of each compound in the two following final concentrations of FE $(640,320 \mu \mathrm{g} / \mathrm{mL}), \mathrm{L}(1000,500 \mu \mathrm{g} / \mathrm{mL})$ and L-FE $(1640,820 \mu \mathrm{g} / \mathrm{mL})$, were added into the wells against the two cellular lines. They were incubated for $18 \mathrm{~h}$, at $37{ }^{\circ} \mathrm{C}$ and $5 \% \mathrm{CO}_{2}$. Then the supernatant was retired and to test cell viability, both human cell types were treated with $110 \mu \mathrm{L}$ medium Krebs- Henseleit buffer (Sigma-Aldrich, St. Louis, MO, USA) as a control, or $100 \mu \mathrm{L}$ Krebs added with $10 \mu \mathrm{L}$ CCK-8 (Cell Counting Kit-8) solution according to the manufacturer instructions. Afterward, they were incubated for $1-2 \mathrm{~h}$ at $37{ }^{\circ} \mathrm{C}$ in a dark place (Cell Counting Kit-8, Sigma-Aldrich, St. Louis, MO, USA). Relative cell viability was determined spectrophotometrically at $450 \mathrm{~nm}$ by quantification of the formazan dye generated by the activity of dehydrogenases in cells, which is directly proportional to the number of living cells.

\subsection{Immune Stimulation}

To measure the immune response of the THP-1 cells differentiated into macrophages as previously described, $2 \times 10^{5}$ cells/well in $900 \mu \mathrm{L}$ completed culture medium RPMI were seeded into a 24 -well plate. Then $100 \mu \mathrm{L}$ of the samples at the same final concentrations described above were added and incubated at $37^{\circ} \mathrm{C}$ and $5 \% \mathrm{CO}_{2}$ for $18 \mathrm{~h}$ before or after $4 \mathrm{~h}$ of stimulation with LPS $(\mathrm{O} 26: \mathrm{B} 6,1 \mu \mathrm{g} / \mathrm{mL})$. A control (untreated and non-stimulated cells) and negative control (untreated and stimulated cells) were obtained. After treatment, 
samples were centrifuged, $1200 \times \mathrm{g}$ rpm for $5 \mathrm{~min}$, and supernatants were recovered and stored at $-20^{\circ} \mathrm{C}$ until cytokine analysis. The concentration of each cytokine, IL-10, and TNF- $\alpha$, released into the supernatants was quantified by using an ELISA kit (Diaclone ELISA Kits, Besancon Cedex, France) according to the manufacturer instructions.

\subsection{In Vitro Gastrointestinal Digestion}

In vitro simulated gastrointestinal digestion of the sea fennel extract (FE) and the liposomes loaded with the extract (L-FE) was carried out according to Alemán et al. [18] with some modifications. Samples were adjusted to $\mathrm{pH} 2.0$ with $\mathrm{HCl} 1 \mathrm{M}$, pepsin (EC 232-629-3, Sigma-Aldrich) was added ( $4 \% w / w$ with respect to FE amount), and the mixture was incubated at $37^{\circ} \mathrm{C}$ for $2 \mathrm{~h}$ (GD, gastric digestion). The $\mathrm{pH}$ was then adjusted to 5.3 with $\mathrm{NaHCO}_{3} 0.9 \mathrm{M}$ and further to $\mathrm{pH} 7.5$ with $\mathrm{NaOH} 1 \mathrm{M}$. After the addition of bile salts $(160 \mathrm{mM})$ and pancreatin (EC 232-468-9, Sigma-Aldrich) (4\% $w / w$ with respect to FE amount), the mixture was incubated at $37^{\circ} \mathrm{C}$ for $2 \mathrm{~h}$ (GID, gastrointestinal digestion). Digestion was finished by heating at $90{ }^{\circ} \mathrm{C}$ for $10 \mathrm{~min}$ to inactivate the enzymes. The samples were centrifuged at $13,000 \times g$ for $30 \mathrm{~min}$, supernatants digested with pepsin (GD) and subsequently digested with pancreatin (GID) were stored at $-20{ }^{\circ} \mathrm{C}$ until use.

\subsection{Intestinal Absorption}

Caco- 2 cells were seeded at a density of $3 \times 10^{4}$ cell $/ \mathrm{cm}^{2}$ in Transwell inserts with a polycarbonate semipermeable membrane $(6.4 \mathrm{~mm}$ diameter and $0.4 \mu \mathrm{m}$ pore size, Corning Costar, Corning, NY, USA) placed in 24-well plastic plates. A fresh culture medium with cells $(0.5 \mathrm{~mL})$ was added to the apical $(\mathrm{AP})$ side and $1.5 \mathrm{~mL}$ of blank culture medium was added to the basolateral chamber. The medium in both the AP and BL sides was changed every 2-3 days. Monolayers were formed after culturing for 21 days. The integrity of the cell layer was evaluated by measurement of Transepithelial/transendothelial electrical resistance (TEER) with Millicell-ERS equipment (Millipore, MA, USA). Monolayers with TEER of $>350$ were used for the experiments.

To measure the apical-to-basolateral permeability, the culture medium was withdrawn and both the apical side of cell monolayers and the basolateral chambers were washed with modified Hank's balanced salt solution (HBSS, Lowell, MA, USA). Then, $1.5 \mathrm{~mL}$ of HBSS $\left(\mathrm{pH} 7.4,37^{\circ} \mathrm{C}\right.$ ) was added to the basal chamber of the Transwell insert, and $0.5 \mathrm{~mL}$ of the samples (FE and L-FE) dissolved in HBSS (Lowell, MA, USA) were added to the apical side. After incubation at $37^{\circ} \mathrm{C}, 0.5 \mathrm{~mL}$ of the basal solution was collected after 60 and $180 \mathrm{~min}$. The intestinal absorption was determined by calculating the percentage of chlorogenic acid that passes through the membrane with respect to the initial amount of chlorogenic acid in each sample.

\subsection{Determination of Phenolic Compounds}

The profile of phenolic compounds in both FE and L-FE samples was determined before and after simulated gastrointestinal digestion (GID). In this regard, a middle step immediately after gastric digestion (GD) was also considered. The chlorogenic acid quantification was conducted in FE, L-FE, digest, and Caco-2 cells permeate samples. Analyses were performed by reverse-phase high-performance liquid chromatography (RP-HPLC, model SPE-MA10AVP, Shimadzu, Kyoto, Japan) on a C18 analytical column, following the procedure described in Alemán et al. [1].

\subsection{Statistical Analysis}

Each experiment was conducted in triplicate and the results were expressed as mean \pm SD. Statistical significances were compared between each treated group and analysis of variance (ANOVA) was performed using SPSS Statistics 26 Software (IBM SPSS Statistics 22 Software, Inc., Chicago, IL, USA). The differences between means were assessed on the basis of confidence intervals by using the Tukey tests with the significance level set at $p \leq 0.05$. 


\section{Results and Discussion}

In a previous study, aqueous and ethanolic extracts of sea fennel, as well as liposomes of phosphatidylcholine (PC) from soybean lecithin loaded with these extracts, were already characterized [1]. Likewise, their antioxidant properties were evaluated, observing that ethanolic extracts showed higher antioxidant properties as expected but lower encapsulation efficiency. In order to delve into their biological properties, in the present work, choosing the aqueous extract for its higher encapsulation efficiency was considered more appropriate.

Firstly, the possible cytotoxicity of the extract (FE), the empty liposomes (L), and the encapsulated extract in the liposomes (L-FE) was evaluated, as well as their antiinflammatory effect.

\subsection{Cellular Viability}

Cell viability of both THP- 1 and Caco- 2 cells evaluated after $18 \mathrm{~h}$ of incubation with the sea fennel aqueous extract (FE), the phosphatidylcholine liposomal dispersion (L), and the corresponding liposomes loaded with sea fennel extract (L-FE), is shown in Figure 1. The viability of the THP-1 cells against the tested samples was carried out as a prerequisite to evaluate their immune response, i.e., to assess their pro- or anti-inflammatory effect. Since the biocompatibility of the samples depends on both the biological properties and the concentration, the samples were tested at two different concentrations after incubation with THP-1 and Caco-2 cells, as mentioned above.
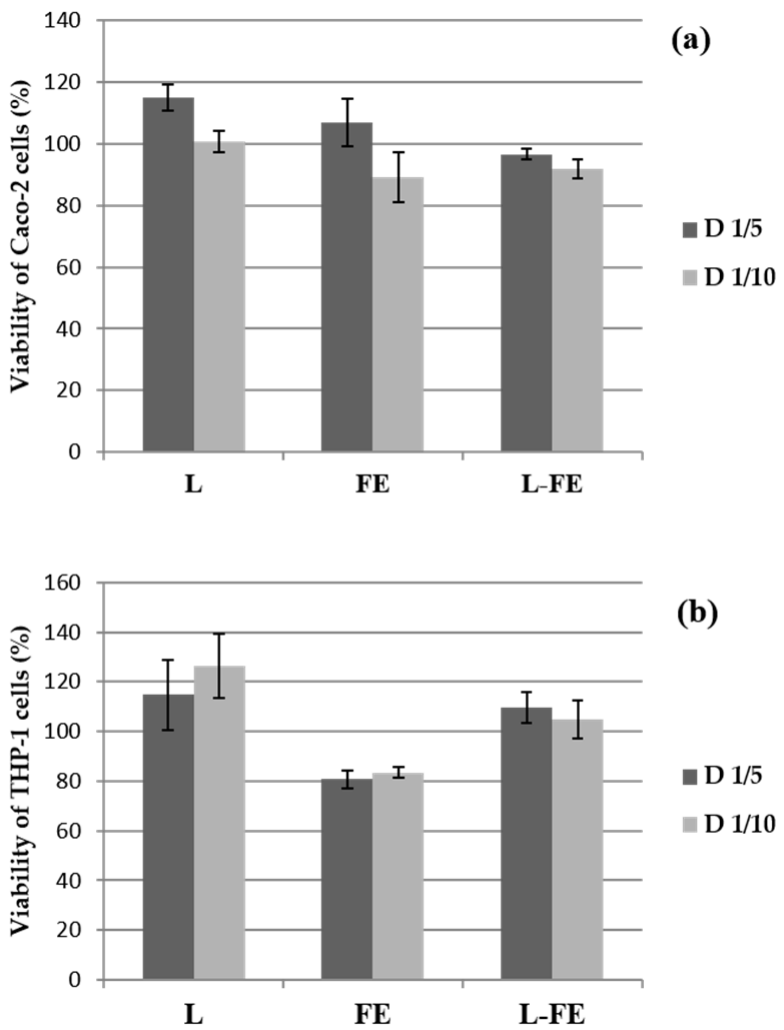

Figure 1. Percentage of viability of Caco-2 (a) and THP-1 cells (b) after incubation during $18 \mathrm{~h}$ with the samples at the two assayed concentrations: L (empty liposome), FE (sea fennel extract), and L-FE (liposome loaded with sea fennel extract). D 1/5 and D 1/10 indicate 1/5 and 1/10 dilutions of each sample, respectively (see Methods). Data show the mean \pm S.D. $(n=3)$.

Cell viability was very high (Figure $1 \mathrm{a}, \mathrm{b}$ ) in all samples tested at both concentrations. Therefore, the samples were not cytotoxic since the percentage of viability was not below $80 \%$ in any of the cases. The increase in viability (approximately $120 \%$ ) observed in some 
samples was also detected by Angius \& Floris [19], who attributed this fact to inconsistent MTT absorbance values that do not correspond to a real increase in viability and are produced by interferences with sample compositions, for instance, with the lipid nature of liposomes. According to these authors, the chemicals and/or their conditions could affect the dehydrogenase activity in viable cells, which could cause a discrepancy between the actual number of viable cells and the number of cells determined by the Cell Counting Kit- 8 .

\subsection{Anti-Inflammatory Activity on THP-1 Cells}

The biocompatibility of the different samples (FE, L, and L-FE) in contact with THP-1 cells is a premise to study the immune response to verify the possible cytokine release that is induced by the action of these samples.

For this study, THP-1 cells differentiated into macrophages were used in two assays to evaluate the anti- and pro-inflammatory effects of FE, L, and L-FE through the induced secretion of both IL-10 (Figure 2) and TNF- $\alpha$ cytokines (Figure 3). In a first assay, the THP-1 cells were first incubated with the samples and subsequently stimulated with LPS, to verify their protective anti-inflammatory activity. In parallel, a second assay, in which macrophages were initially stimulated with LPS and then exposed to the studied samples, was carried out to investigate their ability to downregulate the inflammation response, as previously described by De Marco et al. [8].
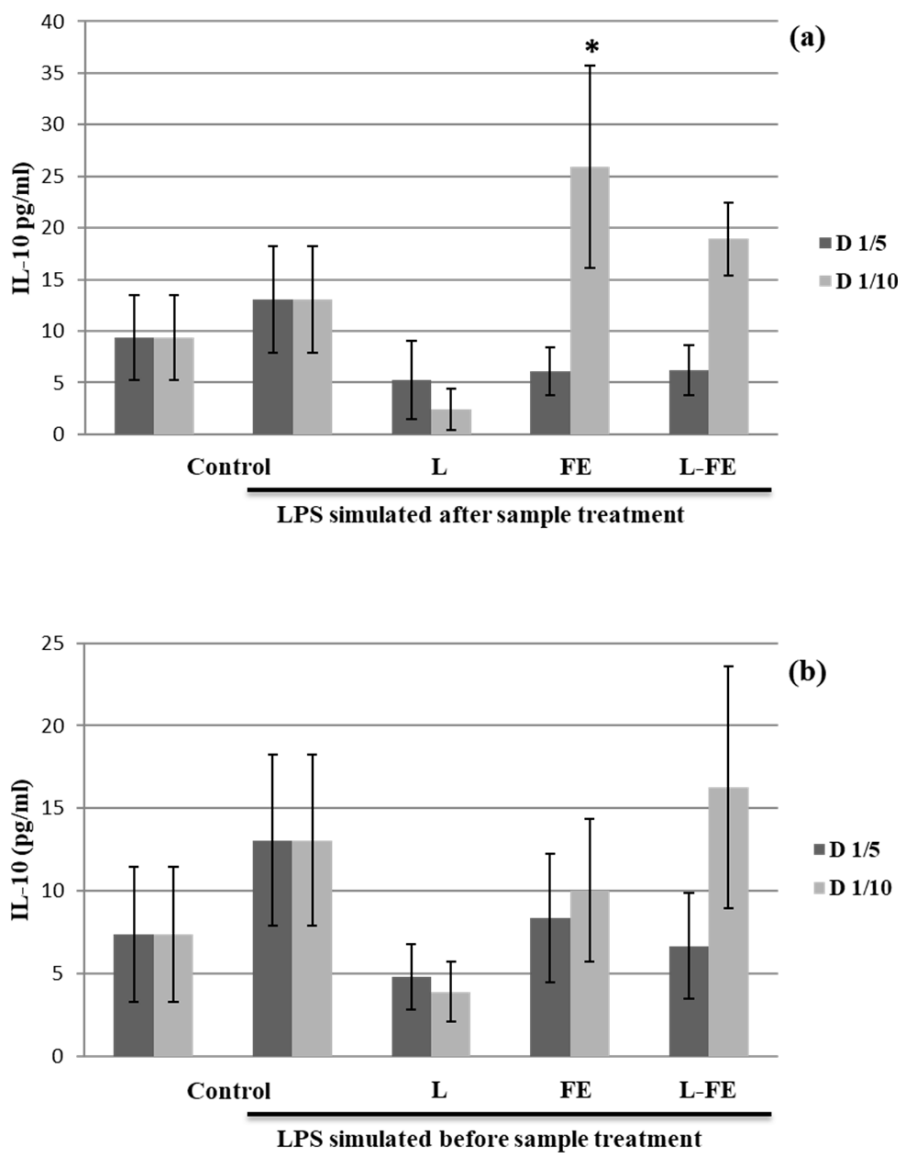

Figure 2. Effects of incubation with samples on IL-10 production in the THP-1 cells. The THP-1 cells differentiated to macrophages were incubated with no sample (Control), empty liposome (L), free fennel extract (FE), and liposome loaded with fennel extract (L-FE) for $18 \mathrm{~h}$ before (a) and after (b) treated with LPS for $4 \mathrm{~h}$. D 1/5 and D 1/10 indicate 1/5 and 1/10 dilutions of each sample, respectively (see Methods). Data are expressed as mean \pm S.D. $(n=3)$ for each dilution. ${ }^{*} p \leq 0.05$ vs. LPS stimulated control cells by Tukey test. 

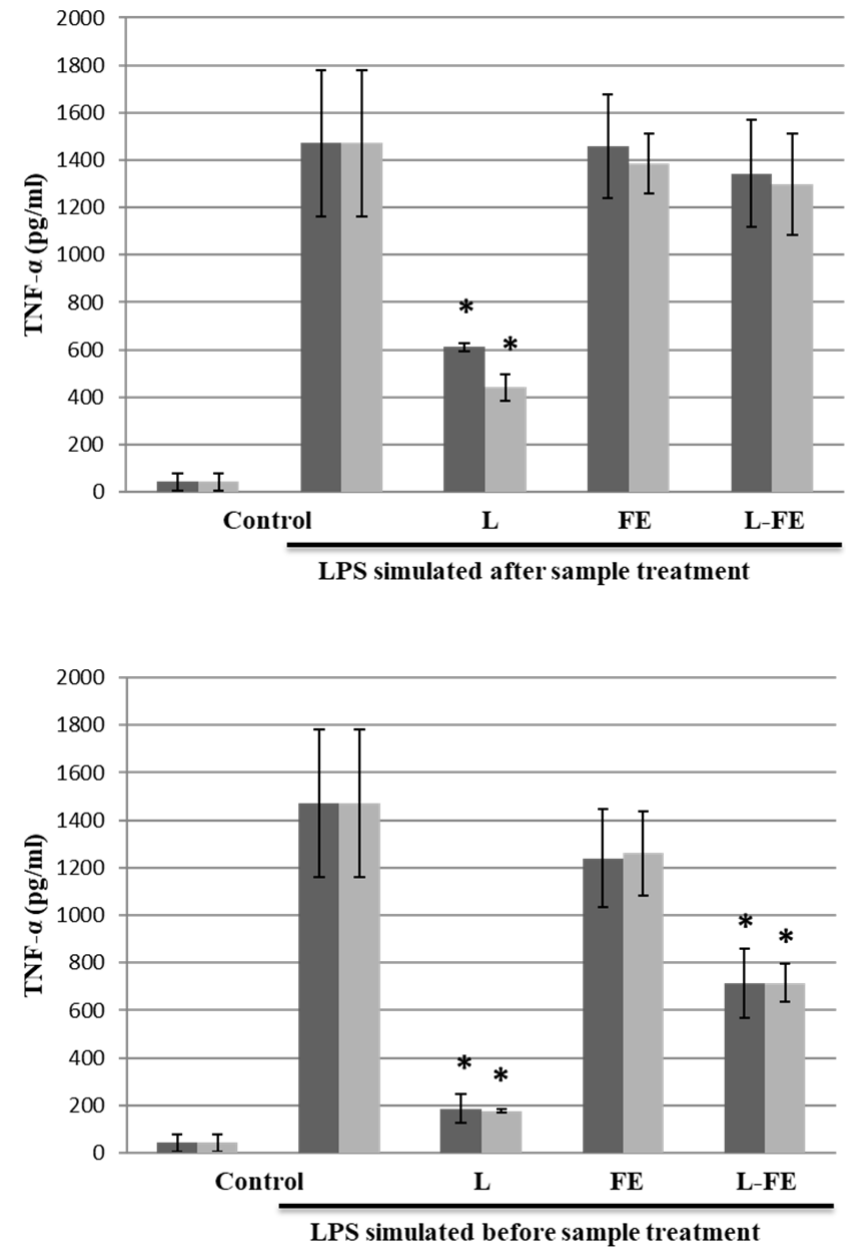

(a)

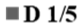

$=$ D $1 / 10$

(b)

-D 1/10

Figure 3. Effects of incubation with samples on TNF- $\alpha$ production in the THP-1 cells. The THP-1 cells differentiated to macrophages were incubated with no sample (Control), empty liposome (L), free fennel extract (FE), and liposome loaded with fennel extract (L-FE) for $18 \mathrm{~h}$ before (a) and after (b) treated with LPS for $4 \mathrm{~h}$. D 1/5 and D 1/10 indicate 1/5 and 1/10 dilutions of each sample, respectively (see Methods). Data are expressed as mean \pm S.D. $(n=3)$ for each dilution. ${ }^{*} p \leq 0.05$ vs. LPS stimulated control cells by Tukey test.

The data obtained from our study showed that only the supernatant recovered from the THP-1 cells incubated with the sea fennel aqueous extract (FE) at lower concentration (320 $\mathrm{gg} / \mathrm{mL}, \mathrm{D} 1 / 10)$ and before LPS stimulation (assay 1) significantly induced Il-10 secretion (Figure 2a). However, FE could contain some components able to inhibit IL-10 production at high concentrations. Nevertheless, when macrophages are in an inflammatory state induced by pretreatment with LPS (assay 2), no induction of IL-10 was noted in any of the samples tested (Figure 2b). Therefore, the extract could be considered as an antiinflammatory agent in a preventive way; however, once inflammation occurs, it does not show any effect on IL-10 secretion.

On the other hand, a decrease in TNF- $\alpha$ production was observed for the empty liposomes (L) in the THP-1 supernatants that were first pretreated with the samples and then stimulated with LPS (assay 1) (Figure 3a). In addition, when macrophages in an inflammatory state (induced by LPS) were later incubated with the samples (assay 2), both $\mathrm{L}$ and L-FE were able to downregulate the inflammation response by reducing significantly TNF- $\alpha$ secretion (at both concentrations tested), being the effect greater for $L$ than for L-FE (Figure 3b). Therefore, the presence of sea fennel extract appears negatively affect the inhibition of TNF- $\alpha$ production caused by liposomes, maybe because the amount of liposome is lower in L-FE than in L, due to the dilution effect. 
Considering these results (Figure 3), empty liposomes have a preventive effect and are also able of reducing inflammation once it occurs. In contrast, L-FE can only downregulate the inflammation once it occurs, but cannot be used to prevent inflammation.

Diverse authors have used THP-1 cells as an in vitro model for human cells (monocytes and macrophages) in studies on the mechanism of inflammatory diseases [20]. Also, another model proposed in the study of food compounds is based on the use of THP-1 cells as possible modulators of inflammation [21]; THP-1 cells were differentiated into macrophages to test the impact that certain compounds present in food can have on the immune system. This is based on the inflammatory reaction produced as a defense mechanism against foreign bodies or stimuli in the organism [22], macrophages having a fundamental role in this inflammatory reaction.

Regarding the anti-inflammatory activity of liposomes, it has been reported that liposomes from squid skin phospholipids have manifested anti-inflammatory effects, suggesting that they could act as apoptotic mimetics that lead to anti-inflammatory effects [23]. Plangsombat et al. [24], working with liposomes of phosphatidylcholine and cholesterol (ratio 7:3), found some anti-inflammatory activity, although this was greater when asparagus extract was encapsulated, the conditions being more effective at concentrations of 1:5 (extract: liposome). According to Lordan et al. [7], phospholipids could contribute to several inflammatory cascades, including as inflammation mediators both PUFAS, arachidonic acid, oxidized phospholipids, and other fatty acids.

\subsection{Effect of In Vitro Gastrointestinal Digestion}

To determine the bioaccessibility of the sea fennel aqueous extract not encapsulated and encapsulated in liposomes (FE and L-FE), both samples were subjected to a GID process. At the end of the gastric phase (GD, $2 \mathrm{~h}$ with pepsin $4 \% w / w$ at $\mathrm{pH} 2,37^{\circ} \mathrm{C}$ ), the chromatographic profile did not change significantly, showing a slight decrease (less than $5 \%$ ) in the amount of chlorogenic acid in the extract, without any considerable modification in the liposome profile (Figure 4). Some studies have attributed the chlorogenic acid stability during gastric digestion to the acid $\mathrm{pH}$ of the medium, which provides a more suitable environment for the chemical stability of this compound [25].

On the other hand, at the end of the intestinal phase (GID, $2 \mathrm{~h}$ with bile salts and pancreatin $4 \% w / w$ at $\mathrm{pH} 7.2,37^{\circ} \mathrm{C}$ ), chlorogenic acid was much more sensitive to degradation/transformation, and the amount present in the extract decreased by $40 \%$ (Figure 4 , Table 1). The chromatographic profiles also showed an increase and/or the appearance of some unidentified compounds, which could be the result of the transformation of chlorogenic acid or other phenolic compounds present in the extract, as a consequence of enzymatic action, temperature, and/or medium $\mathrm{pH}$. In a previous work of our group, splitting or transformation of chlorogenic acid was also observed when the sea fennel extract was encapsulated and was attributed to the heat effect due to sonication when forming the liposomes [1]. The new compounds formed could correspond to the isomers neochlorogenic or cryptochlorogenic acids $[25,26]$. Also, chlorogenic acid does not appear to be hydrolyzed, since among the new compounds formed, caffeic acid, which is a hydrolysis product, was not identified. With respect to the anti-inflammatory activity, TNF- $\alpha$ release has been previously reported to be inhibited by chlorogenic acid isomers, with cryptochlorogenic acid exhibiting the strongest effect [27]. The presumptively newly formed isomers in the digested sea fennel extract could also have improved the anti-inflammatory activity. 

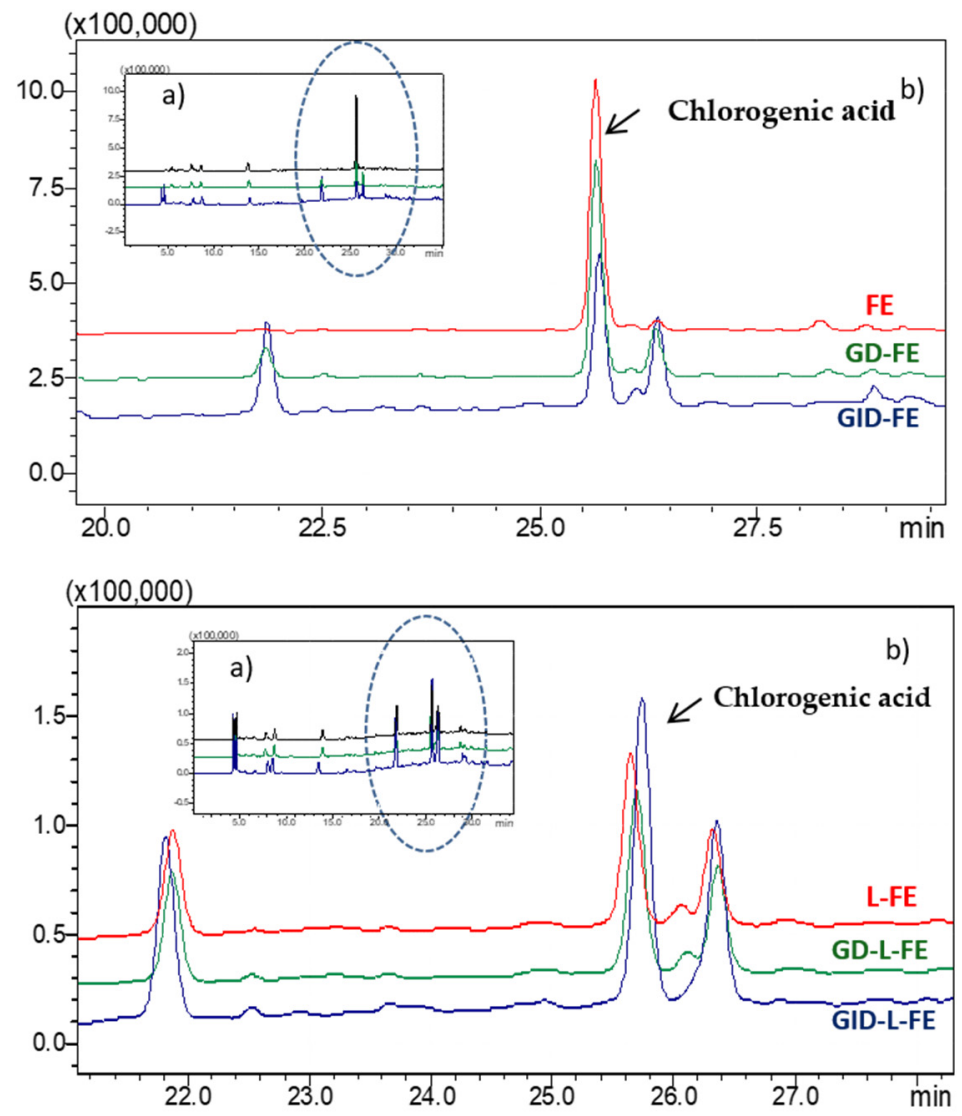

Figure 4. Chromatographic profile at $\lambda 253 \mathrm{~nm}$ of the fennel extract (FE) and liposomes loaded with the extract (L-FE), before and after gastric digestion (GD) and gastrointestinal digestion (GID). (a) full chromatogram, (b) detail of the chromatogram with the most significant changes.

Table 1. Chlorogenic acid concentration $(\mu \mathrm{g} / \mathrm{mL})$ in the sea fennel extract $(\mathrm{FE})$ and the liposomes loaded with the extract (L-FE), before and after the in vitro gastric (GD) and gastrointestinal (GID) digestion.

\begin{tabular}{cc}
\hline & Chlorogenic Acid $(\mu \mathrm{g} / \mathrm{mL})$ \\
\hline FE & $40.3 \pm 0.3^{\mathrm{c}}$ \\
L-FE & $13.4 \pm 0.8^{\mathrm{a}}$ \\
FE-GD & $24.2 \pm 0.3^{\mathrm{b}}$ \\
L-FE-GID & $24.6 \pm 0.5^{\mathrm{b}}$ \\
\hline
\end{tabular}

Data show the mean \pm S.D. $(n=3)$. Different letters $(a, b, c)$ indicate significant differences $(p \leq 0.05)$.

Previous studies suggest that the enzymes present in the small intestine do not usually influence the transformation of chlorogenic acid and that, however, it is the temperature, and especially the alkaline $\mathrm{pH}$ of the medium, that is mainly responsible for the decrease/transformation of this compound [28]. These authors found a $43-45 \%$ decrease in the content of chlorogenic acid after the gastrointestinal digestion of drinks prepared from yerba mate and coffee. Sengul et al. [29], also found that chlorogenic acid, present in a pomegranate extract, was stable during the gastric phase, but suffered a strong degradation at the end of the gastrointestinal digestion process, quantifying, in this case, a loss of $77 \%$.

Conversely, Siracusa et al. [2], studying the effect of gastrointestinal digestion on a sea fennel infusion, found that chlorogenic acid was unstable in both the gastric and intestinal phases, with a final loss of $82 \%$ of the phenolic compound. Other authors, however, have observed high stability throughout the process of in vitro digestion of chlorogenic acid present in food matrices, such as edible flowers and fruit seeds [30-32]. 
In this work, the amount of chlorogenic acid quantified in the liposomes (L-FE) was only $33 \%$ with respect to the amount of chlorogenic acid in the extract (FE) and might correspond to the non-encapsulated part that remains free in the liposomal dispersion [1]. At the end of the digestion process of the liposomes, and contrary to what happens with the extract, the amount of chlorogenic was higher than in the undigested liposome dispersion. Thus, part of the chlorogenic acid that remained protected in the liposomes could have been released during GID, improving its bioaccessibility in the liposomal dispersion. The increase of the phenolic compound in the digested liposomes reached similar values $(p \leq 0.05)$ to those obtained for the digested extract (Table 1), so the amount of the free bioaccessible chlorogenic acid, at first, was similar for the extract and the liposome samples; however, it must be considered that a certain amount of chlorogenic could remain trapped inside the liposomes since according to different authors they partially resist the digestion process [33,34]. Machado et al. [33], observed that liposomes consisting of a mixture of soy lecithin and rice filled with spirulina polyphenols, were partially hydrolyzed during intestinal digestion, thus protecting the phenolic compounds they carried inside from gastric digestion, releasing them into the small intestine (jejunum and ileum). On the other hand, as mentioned above, during gastrointestinal digestion the chlorogenic acid released from the liposomes may also undergo transformation processes. Marín-Peñalver et al. [34], observed how the bioaccessibility of the active compound increased after a simulated GID in the case of soy phosphatidylcholine liposomes loaded with protein hydrolysate, suggesting it is due to a partial disintegration of the liposomes.

\subsection{Intestinal Absorption}

To evaluate the bioavailability of chlorogenic acid present in the sea fennel extract, both the extract (FE) and the liposomal dispersion (L-FE) were analyzed before and after being subjected to the simulated gastrointestinal digestion process. A well-established model of absorption, which consisted of bicameral permeable supports (Transwell) where Caco- 2 cells were seeded and incubated until the formation of a differentiated monolayer and thus, emulated the passage of the extract through the small intestine, was used.

As can be seen in Table 2, the amount of chlorogenic acid that passed through the Caco2 cell monolayer increased over time, although the difference was found to be significant $(p \leq 0.05)$ only for the free extract. However, the in vitro permeability of the phenolic compound, in general, was limited, being the content in the basolateral compartment only $1.4-1.6 \%$ of the initial amount after $3 \mathrm{~h}$ of incubation, without finding significant differences regardless of the encapsulation of the extract. The amount of chlorogenic acid passing through the membrane was therefore much lower than the free amount present in both the extract and the liposomal dispersion (non-encapsulated free fraction). In similar studies with coffee extracts, other authors have also found a low absorption of chlorogenic acid. Thus, Konishi \& Kobayashi [11] and Dupas et al. [35], quantified values of less than 1\% and $1.5 \%$ of the chlorogenic acid initially analyzed in the basolateral compartment, while Gómez-Juaristi [13] managed to recover $2.8 \%$ of the chlorogenic acid in the basolateral compartment.

Table 2. Chlorogenic acid (\%) that passed through the CACO-2 cell monolayer after 1 and $3 \mathrm{~h}$ of incubation.

\begin{tabular}{ccc}
\hline & \% Chlorogenic Acid (1 h) & \% Chlorogenic Acid (3 h) \\
\hline FE & $0.83 \pm 0.09^{\mathrm{a} / \mathrm{x}}$ & $1.53 \pm 0.30^{\mathrm{a} / \mathrm{y}}$ \\
L-FE & $0.86 \pm 0.12^{\mathrm{a} / \mathrm{x}}$ & $1.58 \pm 0.43^{\mathrm{a} / \mathrm{x}}$ \\
FE-GID & $0.91 \pm 0.15^{\mathrm{a} / \mathrm{x}}$ & $1.42 \pm 0.61^{\mathrm{a} / \mathrm{x}}$ \\
LFE-GID & $0.90 \pm 0.08^{\mathrm{a} / \mathrm{x}}$ & $1.49 \pm 0.52^{\mathrm{a} / \mathrm{x}}$ \\
\hline
\end{tabular}

Data show the mean \pm S.D. $(n=3)$. The same letter $(a)$ indicates that there are not significant differences $(p \leq 0.05)$ among samples. Different letters $(x, y)$ indicate significant differences $(p \leq 0.05)$ between 1 and $3 \mathrm{~h}$ for the same sample. 
Although several studies have shown that liposomes can cross the intestinal membrane and be absorbed rather easily [36], in the present work we did not detect the presence of liposomes in the basolateral compartment. In this same ex-vivo system [37], observed an increase in intestinal absorption for liposomes of soy lecithin and cholesterol loaded with a hexapeptide with ACE properties, much higher than that of the free peptide, so these authors indicated that the liposomes elaborated under these conditions are absorbable by the intestinal membrane. Using this same type of liposome formulation (soy phosphatidylcholine with cholesterol) but encapsulating chlorogenic acid, Feng et al. [15], conducted an in vivo study in mice, indicating that the encapsulation of chlorogenic acid increased 1.29 times the bioavailability of the phenolic compound and improved its antioxidant effect. Hence, the nature of the liposome may be important for its intestinal absorption capacity.

Different studies described a preferential absorption mechanism for chlorogenic acid, suggesting that transport would preferably occur in an apical-basolateral direction [11-13]. A great difficulty in this type of in vitro study is the instability of phenolic compounds under incubation conditions. Analyzing the content of chlorogenic acid in both the basolateral and apical compartments, we found that after $3 \mathrm{~h}$ of incubation, only $66-68 \%$ of the initial compound was recovered. Gómez-Juaristi [13] recovered a similar percentage of chlorogenic acid to that of this work (70\%), while Scherbl et al. [38], observed an even greater degradation with a loss of up to $60 \%$ after $4 \mathrm{~h}$ of incubation. It must be considered that chlorogenic acid has been determined as the major compound of sea fennel extract, yet the determination of other compounds in the extract, or produced metabolites that could be absorbed, has not been addressed.

In human studies, it was found that, after the intake of $200 \mathrm{~mL}$ of coffee $(20 \mathrm{mg}$ of chlorogenic acids), the maximum concentration of unmetabolized chlorogenic acid in plasma was $2.2 \mathrm{nM}$, while other derivative metabolites (caffeic acid-3-O-sulfate and the sulfated lactones of 3-caffeoylquinic and 4-caffeoylquinic acids) reached maximum concentration values of 20-92 nM [39]. The results of the present work also suggest that most of the chlorogenic acid present in the sea fennel extract was not absorbed in the small intestine, and could reach the colon, where it would be susceptible to the action of the colonic microbiota, thus taking place the formation of microbial metabolites that could be subsequently absorbed, and/or presenting a possible prebiotic effect, as described by Jaquet et al. [40], for an extract of coffee rich in chlorogenic acid. According to Rechner et al. [41], chlorogenic acid, through two different transformation routes, with intermediate metabolites that can be absorbed by the large intestine or by the colon, could give rise to 3hydroxyhypuric or hippuric acid, respectively, in the last transformation in the liver. Future studies are needed to assess whether liposomes, and the chlorogenic acid encapsulated in them, could reach the colon and be equally transformed by the colonic microbiota.

\section{Conclusions}

In conclusion, this work shows that the food components used (aqueous sea fennel extract and soy phosphatidylcholine liposome) had the in vitro capacity to decrease the inflammation response on THP-1 cells, being the effect of liposomes on TNF- $\alpha$ (proinflammatory) especially significant, while that of the sea fennel extract on IL-10 (anti-inflammatory effect) was less evident. Further studies, such as gene-expression analysis and the identification of mechanisms associated with anti-inflammatory activities, would be required to amplify the knowledge, given their possible use to improve human intestinal inflammation.

The sea fennel extract was susceptible to degradation/transformation during the gastrointestinal digestion process, with a decrease in the chlorogenic acid content of $40 \%$. Part of the chlorogenic acid encapsulated in the liposomes was released during the intestinal phase of digestion so that at the end of the in vitro GID the amount of free bioaccessible chlorogenic was similar in the extract and in the liposomal dispersion. However, in the liposomal dispersion, a large amount of the extract could remain inside the liposomes. The intestinal absorption of chlorogenic acid, studied through a monolayer of Caco-2 cells, is limited, so that most of the free chlorogenic acid, as well as that which remains encapsulated 
in the liposomes, should reach the colon. Future studies are necessary to determine the transformation and the effect of liposomes in the colonic microbiota.

Author Contributions: A.A.P.: Conceptualization, formal analysis, methodology, investigation, writing-original draft preparation, writing—review \& editing. D.M.-P.: Formal analysis, methodology, investigation. P.F.d.P.: Formal analysis, methodology, investigation, Writing-Review \& Editing. M.d.C.G.-G.: Conceptualization, investigation, writing-review \& editing, supervision, project administration, funding acquisition. P.M.G.: Conceptualization, investigation, writing-original draft, Writing-review \& editing, supervision, project administration, funding acquisition. All authors have read and agreed to the published version of the manuscript.

Funding: This work was supported by the Spanish Ministry of Economy and Competitiveness project NANOALIVAL AGL2017-84161, cofounded with ERDF (European Regional Development Fund) and CSIC -202070E218.

Institutional Review Board Statement: Not applicable.

Informed Consent Statement: Not applicable.

Data Availability Statement: All data relevant to the study are included in the article.

Acknowledgments: The authors are grateful for the financial support provided by MINECO (Spain) and European Regional Development Fund (ERDF), through project NANOALIVAL AGL2017-84161, and by CSIC through project 202070E218

Conflicts of Interest: The authors declare no conflict of interest.

\section{References}

1. Alemán, A.; Marín, D.; Taladrid, D.; Montero, P.; Gómez-Guillén, M.C. Encapsulation of antioxidant sea fennel (Crithmum maritimum) aqueous and ethanolic extracts in freeze-dried soy phosphatidylcholine liposomes. Food Res. Int. 2019, 119, 665-674. [CrossRef]

2. Siracusa, L.; Kulisic-Bilusic, T.; Politeo, O.; Krause, I.; Dejanovic, B.; Ruberto, G. Phenolic composition and antioxidant activity of aqueousinfusions from Capparisspinosa L. and Crithmum maritimum L. before and after submission to a two-step in vitro digestion model. J. Agric. Food Chem. 2011, 59, 12453-12459. [CrossRef]

3. Sánchez-Faure, A.; Calvo, M.M.; Pérez-Jiménez, J.; Martín-Diana, A.B.; Rico, D.; Montero, P.; López-Caballero, M.E.; MartínezAlvarez, O. Exploring the potential of common iceplant, seaside arrowgrass and sea fennel as edible halophytic plants. Food Res. Int. 2020, 137, 109613. [CrossRef] [PubMed]

4. Girsang, E.; Lister, I.N.E.; Ginting, C.N.; Nasution, S.L.; Suhartina, S.; Munshy, U.Z.; Rizal, R.; Widowati, W. Antioxidant and Anti-Inflammatory activity of Chlorogenic Acid on Lead Induced Fibroblast Cells. J. Phys. Conf. Ser. 2019, 1374, 012006. [CrossRef]

5. Toma, L.; Sanda, G.M.; Niculescu, L.S.; Deleanu, M.; Sima, A.V.; Stancu, C.S. Phenolic Compounds Exerting Lipid-Regulatory, Anti-Inflammatory and Epigenetic Effects as Complementary Treatments in Cardiovascular Diseases. Biomolecules 2020, 10, 641. [CrossRef]

6. Islam, M.T.; Tabrez, S.; Jabir, N.R.; Ali, M.; Kamal, M.A.; da Silva Araújo, L.; de Oliveira Santos, J.V.; Oliveira Ferreira da Mata, A.M.; Sousa de Aguiar, R.P.; De Carvalho Melo Cavalcante, A.A. An Insight into the Therapeutic Potential of Major Coffee Components. Drug Metab. 2018, 19, 544-556. [CrossRef] [PubMed]

7. Lordan, R.; Tsoupras, A.; Zabetakis, I. Phospholipids of Animal and Marine Origin: Structure, Function, and Anti-Inflammatory Properties. Molecules 2017, 22, 1964. [CrossRef]

8. De Marco, S.; Sichetti, M.; Muradyan, D.; Piccioni, M.; Traina, G.; Pagiotti, R.; Pietrella, D. Probiotic Cell-Free Supernatants Exhibited Anti-Inflammatory and Antioxidant Activity on Human Gut Epithelial Cells and Macrophages Stimulated with LPS. Evid. Based Complement. Altern. Med. 2018, 18, 1756308. [CrossRef]

9. Gee, J.M.; DuPont, M.S.; Rhodes, M.J.; Johnson, I.T. Quercetin glucosides interact with the intestinal glucose transport pathway. Free Radic. Biol. Med. 1998, 25, 19-25. [CrossRef]

10. Olthof, M.R.; Hollman, P.C.; Katan, M.B. Chlorogenic acid and caffeic acid are absorbed in humans. J. Nutr. 2011, 131 , 66-71. [CrossRef]

11. Konishi, Y.; Kobayashi, S. Transepithelial transport of chlorogenic acid, caffeic acid, and their colonic metabolites in intestinal caco-2 cell monolayers. J. Agric. Food Chem. 2004, 52, 2518-2526. [CrossRef] [PubMed]

12. Farrell, T.L.; Gómez-Juaristi, M.; Poquet, L.; Redeuil, K.; Nagy, K.; Renouf, M.; Williamson, G. Absorption of dimethoxycinnamic acid derivatives in vitro and pharmacokinetic profile in human plasma following coffee consumption. Mol. Nutr. Food Res. 2012, 56, 1413-1429. [CrossRef]

13. Gómez-Juaristi, M. Metabolism of Dietary Flavonoids and Hydroxycinnamic Acids. In Vitro Transport Studies and Determination of Bioavailability in Humans. Ph.D. Thesis, Complutense University of Madrid, Madrid, Spain, 2015. 
14. Li, Z.; Jiang, H.; Xu, C.; Gu, L.A. Review: Using nanoparticles to enhance absorption and bioavailability of phenolic phytochemicals. Food Hydrocoll. 2015, 43, 153-164. [CrossRef]

15. Feng, Y.; Sun, C.; Yuan, Y.; Zhu, Y.; Wan, J.; Firempong, C.K.; Omari-Siaw, E.; Xu, Y.; Pu, Z.; Yu, J.; et al. Enhanced oral bioavailability and in vivo antioxidant activity of chlorogenic acid via liposomal formulation. Int. J. Pharm. 2016, 501, 342-349. [CrossRef]

16. Manach, C.; Williamson, G.; Morand, C.; Scalbert, A.; Remesy, C. Bioavailability and bioefficacy of polyphenols in humans. I. Review of 97 bioavailability studies. Am. J. Clin. Nutr. 2015, 81, 230-242. [CrossRef]

17. Lund, M.E.; To, J.; O'Brien, B.A.; Donnelly, S. The choice of phorbol 12-myristate 13-acetate differentiation protocol influences the response of THP-1 macrophages to a pro-inflammatory stimulus. J. Immunol. Methods 2016, 430, 64-70. [CrossRef] [PubMed]

18. Alemán, A.; Gómez-Guillén, M.C.; Montero, P. Identification of ACE-inhibitory peptides from squid skin collagen after in vitro gastrointestinal digestion. Food Res. Int. 2013, 54, 790-795. [CrossRef]

19. Angius, F.; Floris, A. Liposomes and MTT cell viability assay: An incompatible affair. Toxicol. In Vitro 2015, 29, 314-319. [CrossRef] [PubMed]

20. Ueki, K.; Tabeta, K.; Yoshie, H.; Yamazaki, K. Self-heat shock protein 60 induces tumour necrosis factor- $\alpha$ in monocyte-derived macrophage: Possible role in chronic inflammatory periodontal disease. Clin. Exp. Immunol. 2002, 127, 72-77. [CrossRef] [PubMed]

21. Chanput, W.; Mes, J.; Vreeburg, R.A.M.; Savelkoul, H.F.J.; Wichers, H.J. Characterization of polarized THP-1 macrophages and polarizing ability of LPS and food compounds. Food Funct. 2013, 4, 266-276. [CrossRef] [PubMed]

22. Rahimia, K.; Ahmadia, A.; Hassanzadeha, K.; Soleimanib, Z.; Sathyapalanc, T.; Mohammadia, A.; Sahebkard, A. Targeting the balance of $\mathrm{T}$ helper cell responses by curcumin in inflammatory and autoimmune states. Autoimmun. Rev. 2019, 18, 738-748. [CrossRef]

23. Yi-Feng, K.; Yi-Hsieng, S.W.; Chung-His, C.; Shih-Guei, F.; Cheng-Wei, L.; Huey-Jine, C.; Yi-Chen, C. Manufacture and characterization of antiinflammatory liposomes from jumbo flying squid (Dosidicus gigas) skin phospholipid extraction. Food Funct. 2018, 9 , 3986-3996.

24. Plangsombat, N.; Rungsardthong, K.; Kongkaneramit, L.; Waranuch, N.; Sarisuta, N. Anti-inflammatory activity of liposomes of Asparagus racemosus root extracts prepared by various methods. Exp. Ther. Med. 2016, 12, 2790-2796. [CrossRef] [PubMed]

25. Bermúdez-Soto, M.J.; Tomás-Barberán, F.A.; García-Conesa, M.T. Stability of polyphenols in chokeberry (Aronia melanocarpa) subjected to in vitro gastric and pancreatic digestion. Food Chem. 2007, 102, 865-874. [CrossRef]

26. Dawidowicz, A.L.; Typek, R. The influence of $\mathrm{pH}$ on the thermal stability of 5-O-caffeoylquinic acids in aqueous solutions. Eur. Food Res. Technol. 2011, 233, 223-232. [CrossRef]

27. Weber, L.; Mahdi, D.H.; Jankuhn, S.; Lipowicz, B.; Vissiennon, C. Bioactive Plant Compounds in Coffee Charcoal (Coffeae carbo) Extract Inhibit Cytokine Release from Activated Human THP-1 Macrophages. Molecules 2019, 24, 4263. [CrossRef] [PubMed]

28. Baeza, G.; Sarriá, B.; Bravo, L.; Mateos, R. Polyphenol content, in vitro bioaccessibility and antioxidant capacity of widely consumed beverages. J. Sci. Food Agric. 2017, 98, 1397-1406. [CrossRef] [PubMed]

29. Sengul, H.; Surek, E.; Nilufer-Erdil, D. Investigating the effects of food matrix and food components on bioaccessibility of pomegranate (Punica granatum) phenolics and anthocyanins using an in-vitro gastrointestinal digestion model. Food Res. Int. 2014, 62, 1069-1079. [CrossRef]

30. Mosele, J.I.; Macia, A.; Romero, M.P.; Motilva, M.J.; Rubi, L. Application of in vitro gastrointestinal digestion and colonic fermentation models to pomegranate products (juice, pulp and peel extract) to study the stability and catabolism of phenolic compounds. J. Func. Foods 2015, 14, 529-540. [CrossRef]

31. Chen, G.L.; Chen, S.G.; Xie, Y.Q.; Chen, F.; Zhao, Y.Y.; Luo, C.X.; Gao, Y.Q. Total phenolic, flavonoid and antioxidant activity of 23 edible flowers subjected to in vitro digestion. J. Func. Foods 2015, 17, 243-259. [CrossRef]

32. He, Z.; Tao, Y.; Zeng, M.; Zhang, S.; Tao, G.; Qin, F.; Chen, J. High pressure homogenization processing, thermal treatment and milk matrix affect in vitro bioaccessibility of phenolics in apple, grape and orange juice to different extents. Food Chem. 2016, 200, 107-116. [CrossRef]

33. Machado, A.R.; Pinheiro, A.C.; Vicente, A.A.; Souza-Soares, L.A.; Cerqueira, M. Liposomes loaded with phenolic extracts of spirulina LEB-18: Physicochemical characterization and behavior under simulated gastrointestinal conditions. Food Res. Int. 2019, 120, 656-667. [CrossRef]

34. Marín-Peñalver, D.; Alemán, A.; Gómez-Guillén, M.C.; Montero, P. Carboxymethyl cellulose films containing nanoliposomes loaded with an angiotensin-converting enzyme inhibitory collagen hydrolysate. Food Hydrocoll. 2019, 64, 553-560. [CrossRef]

35. Dupas, C.; Baglieri, A.M.; Ordonaud, C.; Tomé, D.; Maillard, M.N. Chlorogenic acid is poorly absorbed, independently of the food matrix: A Caco-2 cells and rat chronic absorption study. Mol. Nutr. Food Res. 2006, 50, 1053-1060. [CrossRef] [PubMed]

36. Sangsuriyawong, A.; Limpawattana, M.; Siriwan, D.; Klaypradit, W. Properties and bioavailability assessment of shrimp astaxanthin loaded liposomes. Food Sci. Biotechnol. 2019, 28, 529-537. [CrossRef] [PubMed]

37. Zhang, H.; Yokoyama, W.H.; Zhang, H. Concentration-dependent displacement of cholesterol in micelles by hydrophobic rice bran protein hydrolysates. J. Sci. Food Agric. 2012, 92, 1395-1401. [CrossRef]

38. Scherbl, D.; Muentnich, S.; Richling, E. In vitro absorption studies of chlorogenic acids from coffee using the Ussing chamber model. Food Res. Int. 2014, 63 Pt C, 456-463. [CrossRef] 
39. Stalmach, A.; Mullen, W.; Barron, D.; Uchida, K.; Yokota, T.; Cavin, C.; Steiling, H.; Williamson, G.; Crozier, A. Metabolite profiling of hydroxycinnamate derivatives in plasma and urine after the ingestion of coffee by humans: Identification of biomarkers of coffee consumption. Drug Metab. Dispos. 2009, 37, 1749-1758. [CrossRef]

40. Jaquet, M.; Rochat, I.; Moulin, J.; Cavin, C.; Bibiloni, R. Impact of coffee consumption on the gut microbiota: A human volunteer study. Int. J. Food Microbiol. 2009, 130, 117-121. [CrossRef] [PubMed]

41. Rechner, A.R.; Smith, M.A.; Kuhnle, G.; Gibson, G.R.; Debnam, E.S.; Srai, S.K.S.; Moore, K.P.; Rice-Evans, C. Colonic metabolism of dietary polyphenols: Influence of structure on microbial fermentation products. Free Rad. Biol. Med. 2004, 36, 212-225. [CrossRef] [PubMed] 